\title{
Direct Oral Anticoagulants in Atrial Fibrillation: Practical Considerations and Remaining Issues
}

\author{
Jan Beyer-Westendorf ${ }^{1}$ \\ ${ }^{1}$ Thrombosis Research Unit, Department of Medicine I, Division \\ Hematology, University Hospital “Carl Gustav Carus” Dresden, \\ Dresden, Germany \\ Hämostaseologie 2021;41:35-41.
}

\author{
Address for correspondence Jan Beyer-Westendorf, MD, Department \\ of Medicine I, Division of Hematology and Haemostaseology, \\ University Hospital “Carl Gustav Carus” Dresden, Technical University, \\ Fetscherstrasse 74; D-01307 Dresden, Germany \\ (e-mail: jan.beyer@uniklinikum-dresden.de).
}

\begin{abstract}
Keywords

- direct oral anticoagulants

- atrial fibrillation

- stroke

Preventing thromboembolic events, while minimizing bleeding risks, remains challenging when managing patients with atrial fibrillation. Despite large and successful trial programs, several clinical concerns remain which commonly relate to fears of overor underexposure to drugs and unfavorable outcomes. After a short summary of the main phase III trial findings, this short review discusses the evidence and clinical relevance of common clinical concerns (correct direct oral anticoagulant [DOAC] dosing; DOAC in moderate-to-severe renal impairment; and the relevance of fasting, nasogastric tube feeding, or high body mass index) on DOAC plasma levels. Finally, the need for specific DOAC antidotes will be addressed.
\end{abstract}

\section{Introduction}

Patients with atrial fibrillation (AF) have nearly a fivefold increased risk of stroke compared with those without. ${ }^{1}$ To reduce this risk, oral anticoagulation $(O A C)$ is the central and most effective medical intervention. ${ }^{2}$ As a consequence, more than $80 \%$ of the Western AF population receive $O A C$ therapy and over the past 10 years, direct oral anticoagulants (DOACs) have largely replaced vitamin $\mathrm{K}$ antagonists (VKAs) in this indication. ${ }^{3}$ Although both VKAs and DOACs are similarly effective, better safety and treatment persistence as well as better convenience for patients make DOAC the preferred treatment option. This review will summarize the main findings of the phase III DOAC AF trials but mainly focuses on frequently asked questions and unresolved issues.

\section{DOAC Efficacy and Safety in Phase III Trials and Daily Care}

DOACs have a close dose-response relationship leading to predictable anticoagulant effects. As a consequence, fixeddose regimens are established and routine anticoagulation monitoring is not required. ${ }^{2}$

received

October 16, 2020

accepted after revision

December 3, 2020
Using these concepts, all DOACs demonstrated a favorable benefit-risk profile in the pivotal phase III randomized controlled trials, ${ }^{4-8}$ enrolling a total of more than 70,000 AF patients at risk for stroke. ${ }^{8}$ Taken together, DOACs in these trials significantly reduced stroke or systemic embolic events compared with warfarin (relative risk [RR]: $0.81,95 \%$ confidence interval [CI]: 0.73-0.91), which was mainly driven by a reduction in hemorrhagic stroke (RR: $0.49,95 \% \mathrm{CI}: 0.38-0.64$ ). DOACs also achieved a significant reduction of all-cause mortality (RR: $0.90,95 \%$ CI: 0.85-0.95) and intracranial hemorrhage (RR: $0.48,95 \%$ CI: 0.39-0.59), but increased gastrointestinal (GI) bleeding (RR: $1.25,95 \%$ CI: $1.01-1.55)^{8}{ }^{8}$

For all DOACs, a reduced dosage was also investigated for patients perceived to be at high risk for bleeding or DOAC accumulation. These low-dose regimens demonstrated an overall stroke protection similar to warfarin (RR: $1.03,95 \%$ CI: $0.84-1.27)$ and a more favorable bleeding profile (RR: $0.65,95 \%$ CI: $0.43-1.00$ ), but significantly more ischemic strokes were observed (RR: $1.28,95 \% \mathrm{CI}: 1.02-1.60){ }^{8}$

\section{Choice of DOAC Dosage}

The choice and dose of DOACs depend on the individual patient situation, and several factors are used to assess the

$\begin{array}{ll}\text { C } 2021 . \text { Thieme. All rights reserved. } & \text { DOI https://doi.org/ } \\ \text { Georg Thieme Verlag KG, } & \text { 10.1055/a-1329-2430. } \\ \text { Rüdigerstraße 14, } & \text { ISSN 0720-9355. } \\ \text { 70469 Stuttgart, Germany } & \end{array}$


need for DOAC dose reduction: older age, renal impairment, low body weight, and the potential for drug-drug interactions ( - Table 1$)^{9}{ }^{9-12}$ The algorithm for dose reduction is different: apixaban is reduced in patients with two or more characteristics from moderate to severe renal impairment, older age, and low body weight. ${ }^{9}$ The dose of dabigatran should be lowered for moderate to severe renal impairment, older age ( $>80$ years and/or high bleeding risk), and concomitant use of P-glycoprotein (P-gp) inhibitors. ${ }^{10}$ The dose of edoxaban is lowered for moderate to severe renal impairment, low body weight, and concomitant use of P-gp inhibitors. ${ }^{11}$ For rivaroxaban, dose reductions are required for moderate to severe renal impairment only, ${ }^{12}$ because pharmacokinetic/pharmacodynamic (PK/PD) profiles and simulations of drug exposure have shown no effect of age, body weight, gender, or co-medications on drug exposure. ${ }^{13}$ However, in addition to the inconsistent dose reduction criteria for each DOAC, the extent of dose reductions is also variable. While rivaroxaban and dabigatran are reduced by only approximately 25 to $30 \%$, apixaban and edoxaban are reduced by $50 \%$, which may lead to clinically relevant discrepancies of drug exposure and outcomes.
All these licensed dosing recommendations are based on dose reduction criteria, which were prespecified for the phase III trials ${ }^{4-7,13,14}$ based on small-dose finding studies or pharmacological models. Therefore, these criteria have not been rigorously studied and the use of the lower DOAC dose should be limited to patients truly fulfilling these criteria to reduce the risk of undertreatment from unjustified dose reductions. ${ }^{15-18}$

Correctly applied dose-reduction strategies are important for AF patients to achieve the optimal balance between stroke and bleeding risk. Similar to all anticoagulants, effectiveness and safety of DOACs are defined by plasma exposure: higher plasma drug levels will reduce the risk for thromboembolism, while increasing the risk for bleeding. PK analyses from the RE-LY and ENGAGE AF-TIMI 48 trials showed that the probability of major bleeding events increased with increasing DOAC trough plasma concentrations and the risk of stroke/systemic embolism was higher at lower plasma trough concentrations. ${ }^{14,19}$

Consequently, factors that increase the likelihood of very high or very low DOAC plasma concentrations need to be considered and renal impairment, drug-drug

Table 1 Recommended DOAC dosing for patients with atrial fibrillation

\begin{tabular}{|c|c|c|c|c|}
\hline & $\begin{array}{l}\text { Apixaban }{ }^{\text {a }} \text { ( } 5 \mathrm{mg} \\
\text { bid) }\end{array}$ & Dabigatran (150 mg bid) & $\begin{array}{l}\text { Edoxaban } \\
\text { (60 mg od) }\end{array}$ & $\begin{array}{l}\text { Rivaroxaban } \\
(20 \mathrm{mg} \text { od) }\end{array}$ \\
\hline \multicolumn{5}{|l|}{ Age } \\
\hline $75-80$ y & $5 \mathrm{mg}$ bid & Consider $110 \mathrm{mg}$ bid & $60 \mathrm{mg}$ od & $20 \mathrm{mg}$ od \\
\hline$\geq 80 y$ & $\begin{array}{l}2.5 \mathrm{mg} \text { bid with one } \\
\text { other factor }^{\mathrm{a}}\end{array}$ & $110 \mathrm{mg}$ bid & $60 \mathrm{mg}$ od & $20 \mathrm{mg}$ od \\
\hline \multicolumn{5}{|l|}{ Body weight } \\
\hline $50-60 \mathrm{~kg}$ & $\begin{array}{l}2.5 \mathrm{mg} \text { bid with one } \\
\text { other factor }{ }^{\mathrm{a}}\end{array}$ & $150 \mathrm{mg}$ bid & $30 \mathrm{mg}$ od & $20 \mathrm{mg}$ od \\
\hline$<50 \mathrm{~kg}$ & $\begin{array}{l}2.5 \mathrm{mg} \text { bid with one } \\
\text { other factor }{ }^{\mathrm{a}}\end{array}$ & Consider $110 \mathrm{mg}$ bid & $30 \mathrm{mg}$ od & $20 \mathrm{mg}$ od \\
\hline $\begin{array}{l}\text { Serum } \\
\text { creatinine } \\
\geq 1.5 \mathrm{mg} / \mathrm{dL}\end{array}$ & $\begin{array}{l}2.5 \mathrm{mg} \text { bid with one } \\
\text { other factor }{ }^{\mathrm{a}}\end{array}$ & - & - & - \\
\hline \multicolumn{5}{|l|}{$\mathrm{CrCl}$} \\
\hline $30-49 \mathrm{~mL} / \mathrm{min}$ & $5 \mathrm{mg}$ bid & 150 or $110 \mathrm{mg}$ bid & $30 \mathrm{mg}$ od & $15 \mathrm{mg}$ od \\
\hline $15-29 \mathrm{~mL} / \mathrm{min}$ & $2.5 \mathrm{mg}$ bid & Contraindicated/75 mg bid ${ }^{\mathrm{c}}$ & $30 \mathrm{mg}$ od & $15 \mathrm{mg}$ od \\
\hline$<15 \mathrm{~mL} / \mathrm{min}$ & Contraindicated & Contraindicated & Contraindicated & Contraindicated \\
\hline \multicolumn{5}{|c|}{ Concomitant medication $^{\mathrm{b}}$} \\
\hline Cyclosporine & - & Contraindicated & $30 \mathrm{mg}$ od & - \\
\hline Dronedarone & 0 & Contraindicated/consider $75 \mathrm{mg}$ bid $^{c}$ & $30 \mathrm{mg}$ od & Not recommended \\
\hline Erythromycin & - & - & $30 \mathrm{mg}$ od & $20 \mathrm{mg}$ od \\
\hline Ketoconazole & Not recommended & Contraindicated/consider $75 \mathrm{mg}$ bid $^{c}$ & $30 \mathrm{mg}$ od & Not recommended \\
\hline Verapamil & $5 \mathrm{mg}$ bid & 150 or $110 \mathrm{mg}$ bid & $60 \mathrm{mg}$ od & - \\
\hline
\end{tabular}

Abbreviations: bid, twice daily; $\mathrm{CrCl}$, creatinine clearance; DOAC, non-vitamin $\mathrm{K}$ antagonist oral anticoagulant; od, once daily.

${ }^{\mathrm{a}}$ For apixaban, $2.5 \mathrm{mg}$ bid is indicated in patients with two or more of the following characteristics; age $\geq 80$ years, body weight $\leq 60 \mathrm{~kg}$, and serum creatinine $\geq 1.5 \mathrm{mg} / \mathrm{dL}(133 \mu \mathrm{mol} / \mathrm{L})$.

bincomplete list. See individual labels for more information.

'Dabigatran $75 \mathrm{mg}$ is only available in the United States, and the use of dabigatran in these patients may be contraindicated in other countries. 
interactions, and extremely high body weight are the most common points of discussion amongst DOAC prescribers.

\section{Frequently Asked DOAC Questions of DOAC Prescribers}

\section{How to Use DOAC in Moderate to Severe Renal Impairment?}

Patients with renal dysfunction are at risk of DOAC accumulation. ${ }^{19}$ In patients with a creatinine clearance $[\mathrm{CrCl}]$ between 30 and $50 \mathrm{~mL} / \mathrm{min}$, all DOACs can be used but reduced dosages should be considered with dose reduction criteria being different between DOACs. Apixaban, edoxaban, and rivaroxaban can be used with caution in patients with severe renal disease when $\mathrm{CrCl}$ is 15 to $29 \mathrm{~mL} / \mathrm{min}$, but dabigatran is contraindicated in this situation. However, given the comparatively high renal excretion of edoxaban ( $\sim 50 \%),{ }^{11}$ the author would prefer apixaban or rivaroxaban in this setting.

There is still very limited evidence only on the use of DOACs in patients with end-stage renal disease (ESRD; $\mathrm{CrCl}<15 \mathrm{~mL} / \mathrm{min}$ ). Dabigatran and edoxaban exhibit a relevant renal clearance ${ }^{10,11}$ and are contraindicated in this situation for risk of overexposure. Although apixaban and rivaroxaban are not strictly contraindicated in ESRD or dialysis patients, labels both in the United States and Europe caution to avoid use in this setting due to the lack of clinical data. On the other hand, pharmacological models indicated that the risk of clinically relevant drug accumulation of apixaban or rivaroxaban is $\operatorname{low}^{20}$ and there are several reasons why DOACs may have a role in stroke prevention of dialysis patients in the future ${ }^{21}$ :

- The alternative to use warfarin in ESRD is problematic: renal failure is listed as a contraindication for VKA. ${ }^{22}$

- There is no significant benefit from VKAs versus no anticoagulation with respect to ischemic stroke but an excess risk for major bleeding was observed. ${ }^{23,24}$

- Although studies in this field were inconsistent in study design and quality, this questions the need for anticoagulation in dialysis patients in general and data from an ongoing randomized trial will hopefully clarify the role for VKA in this setting (NCT02886962).

- Evidence for using DOACs in ESRD and dialysis patients is emerging and, so far, has indicated a potential for benefit, ${ }^{25-27}$ although negative results have also been reported. ${ }^{28,29}$

\section{Which Drug-Drug Interactions Are Relevant?}

Clinically relevant drug-drug interactions with DOACs mainly arise from induction or inhibition of CYP3A4 and/or P-gp transport proteins and, much less, from competition with other substrates of these elimination mechanisms. ${ }^{30}$ As a general rule, DOACs neither induce or inhibit CYP enzymes or P-gp. Therefore, DOAC effects on PK of other drugs are very limited. On the other hand, DOACs are all Pgp substrates and drugs that are strong inducers of P-gp expression (such as rifampicin and St. John's wort) decrease
DOAC plasma levels to a clinically relevant degree. Concomitant treatment with such drugs should be avoided or used with caution. ${ }^{31}$ Similarly, strong inhibitors of CYP3A4 will increase DOAC plasma levels but this is clinically relevant only for apixaban and rivaroxaban, since edoxaban and dabigatran metabolism is nearly independent of CYP3A4 enzymes.

However, concomitant treatment with strong inhibitors of both CYP3A4 and P-gp (such as systemic azole-antimycotics or human immunodeficiency virus-protease inhibitors) is contraindicated/not recommended in patients receiving apixaban, dabigatran, or rivaroxaban, and, in patients receiving edoxaban, a dose reduction from 60 to $30 \mathrm{mg}$ once daily is warranted. ${ }^{31}$

The European Heart and Rhythm Association guidance on DOAC use contains very informative and clinically helpful tables, indicating culprit drugs and extent of interactions with DOACs, and the reader is encouraged to refer to this document for further details. ${ }^{31}$

\section{Should DOAC Be Taken with Food or Fasting?}

According to labels, only rivaroxaban at doses higher than $10 \mathrm{mg}$ needs to be taken with food, since absorption of lower doses was found to be independent of the fasting state, whereas plasma exposure from higher dosages increased by $39 \%$ (area under the curve, AUC) when the drug was taken with food. 20

In contrast, labels of apixaban, edoxaban, and dabigatran state that absorption is independent of the fasting status, so, at least theoretically, these drugs could be taken without food. ${ }^{32-34}$ On the other hand, some skepticism may be warranted here.

First, these recommendations are exclusively based on small first-in-human PK studies, which usually study exposure after single-dose applications to healthy volunteers. As a consequence, the effect of fasting status on DOAC absorption in elderly patients who may exhibit chronic intestinal diseases is really unknown.

Second, one of the most relevant side effects of DOAC treatment is upper GI bleeding. It seems plausible to expect a higher risk of GI bleeding, if a drug that carries this risk is routinely taken without food, thus exposing the potentially vulnerable "naked" gastric mucosa to undiluted chemicals (but this may only partially explain the issue of upper GI bleeding from DOAC, since an increase of lower GI and genitourinary is also observed, which is unrelated to direct contact of DOAC with the mucosal layer). Third, every trial with every DOAC lists thromboembolic complications during DOAC therapy, but little is known about the reasons for these therapeutic failures, which may well be based on individual malabsorption due to fasting.

Taken together, irrespective of the liberal recommendations to take most DOACs and dosages with or without food, the author has made it an individual policy to explain the limited evidence behind this to the patients and to routinely recommend DOAC intake with food, irrespective of DOAC type and dosage. 


\section{Can DOAC Be Given via Nasogastric Tubes?}

Patients with AF represent an elderly vulnerable population and some patients may be or may become unable to swallow tablets or capsules. In this situation, the placement of feeding lines such as nasogastric tubes is a clinical routine but raises the question of whether DOAC tablets or dabigatran capsules can be crushed and given with fluids via such tubes. For each DOAC, dedicated studies have been performed, with variable outcomes.

For apixaban, oral administration of $10 \mathrm{mg}$ of apixaban as two crushed $5 \mathrm{mg}$ tablets suspended in water or mixed with applesauce resulted in an AUC reduction of only $16 \%$ compared with standard application. Suspension of a crushed $5 \mathrm{mg}$ tablet in tube nutrition resulted in a drug exposure similar to that seen in other clinical trials involving healthy volunteers receiving a single oral $5 \mathrm{mg}$ tablet dose. ${ }^{33}$

For edoxaban, administration of a crushed $60 \mathrm{mg}$ tablet, either mixed into applesauce or suspended in water and given through a nasogastric tube, resulted in a similar exposure compared with administration of an intact tablet. ${ }^{32}$

For rivaroxaban, administration of a $20 \mathrm{mg}$ tablet administered orally as a crushed tablet mixed in applesauce or suspended in water and administered via a nasogastric tube followed by a liquid meal resulted in an AUC comparable to the AUC after standard application. ${ }^{20}$

In contrast to these reassuring data from direct factor Xa inhibitors, dabigatran is not applied as a tablet (that can be crushed) but as a capsule which contains pellets of the prodrug. The oral bioavailability of dabigatran etexilate increases by $75 \%$ when the pellets are taken without the capsule shell compared with the intact capsule formulation. PRADAXA capsules should therefore not be broken, chewed, or opened before administration. ${ }^{34}$

Taken together, factor Xa inhibitors but not dabigatran can be given via nasogastric tubes. However, the discussed data mainly result from single-exposure healthy-volunteer studies, so readers should apply caution in this setting and limit the application via feeding lines in chronically ill patients to an unavoidable minimum.

\section{Can DOAC Be Used in Very Obese Patients?}

Although DOAC labels only reflect on low-body-weight patients (necessitating DOAC dose reduction for apixaban, edoxaban, and dabigatran), there is widespread concern that the fixed dosing may carry a risk of relative underexposure in extreme obesity ${ }^{35-37}$ and, in 2016, the International Society on Thrombosis and Haemostasis (ISTH) Scientific and Standardization Committee issued a warning against the use of fixed-dose DOACs in patients with a body mass index (BMI) of $>40 \mathrm{~kg} / \mathrm{m}^{2}$ or a weight of $>120 \mathrm{~kg}$, based on lack of evidence for patients at the upper extreme of weight. ${ }^{38}$

However, subgroup analyses in large phase III trials suggest that DOACs are efficacious and well tolerated in obese patients, although the respective patient numbers were low. $^{38-42}$

Recently, several PK/PD studies, case series, and large retrospective claims database analyses have been published which provide reassurance that licensed dosing of DOACs is effective and safe also in very obese patients with BMI $>40 \mathrm{~kg} / \mathrm{m}^{2}{ }^{42-51}$ It can be expected that the current, more cautious ISTH guidance will be updated accordingly in the near future.

\section{Do We Need Specific DOAC Antidotes?}

DOACs are generally safer than VKAs. Because of this, also fragile patients who would previously not have been candidates for VKA therapy now receive DOAC prescriptions. Such patients present vulnerability for spontaneous or traumatic bleedings and, since DOACs are potent anticoagulants, major bleeding complications are not infrequent. Although most of these events are not life-threatening and manageable by short DOAC interruptions, local compression, minor surgery, or transfusion, the widespread use of DOAC leads to an increasing frequency also of major bleeding complications. ${ }^{52}$ Nearly half of them are GI and some $10 \%$ are intracranial bleedings, ${ }^{53,54}$ leading to a frequent request of DOAC-specific reversal strategies with specific antidotes. ${ }^{55}$ In fact, in daily care, more than $50 \%$ of patients older than 60 years presenting with hip fractures or major head trauma are on anticoagulant therapy. ${ }^{56,57}$

To answer the question of "do we need a specific DOAC antidote, the following pragmatic considerations apply:

- Most bleeding complications of DOACs are non-lifethreatening. They can be managed conservatively without specific or unspecific DOAC reversal strategies.

- Most major bleeding complications during DOAC therapy are GI or urogenital bleedings. Again, most of these can be managed conservatively or using dedicated endoscopic strategies to close bleeding lesions. Antidotes are rarely needed in these situations but may be considered in cases of severe diffuse mucosal bleeding unresponsive to conservative or endoscopic treatments or when the bleeding lesion cannot be identified by endoscopy. Typically, such bleedings develop during DOAC overexposure (intoxication or accumulation from deterioration of renal function). Here, DOAC antidotes may indeed play a role and improve bleeding outcome, although the evidence for such treatment decisions is weak.

- For acute life-threatening bleeding, idarucizumab (for dabigatran reversal) and andexanet alfa (for reversal of direct factor Xa inhibitors) have demonstrated effective reversal of DOAC anticoagulation and effectiveness in achieving immediate hemostatic control. ${ }^{58,59}$ However, these trials were performed without comparator treatment, so the benefit of specific antidote reversal over traditional reversal with factor concentrates has yet to be demonstrated. Furthermore, for andexanet alfa, the approval is currently limited to reversal of apixaban and rivaroxaban in cases of major bleeding. Although the author has little doubt that these results can be extended to edoxaban, such use has to be regarded as "off-label" for the time being.

- For DOAC-treated patients in need of urgent surgery, reversal with idarucizumab has been approved for dabigatran-treated patients. In contrast, approval of andexanet alfa is limited to acute, life-threatening bleeding and safety and clinical benefit for patients requiring 
immediate surgery has not been demonstrated so far. Again, such use has to be regarded as "off-label" for the time being.

Another consideration for DOAC reversal is the thrombolytic treatment of acute ischemic events during DOAC therapy. Although DOACs are highly effective to prevent cardioembolic stroke in AF patients, not every ischemic stroke is of cardioembolic nature (which could have been prevented by DOACs) and prothrombotic states may override the clinical efficacy of DOACs in AF. As a result, patients may develop ischemic stroke while being on DOAC therapy. Optimally, such patients present with acute stroke symptoms within the time window for thrombolysis. In this situation, use of idarucizumab or andexanet alfa is a clinical consideration which is supported by some guidelines ${ }^{60-62}$ but not covered by the current labels of these antidote compounds. Therefore, this strategy cannot be generally recommended but may be needed in cases of severe stroke when immediate thrombolysis is the only option to achieve acceptable clinical outcomes. Clearly, the use of antidotes would be off-label in this situation, requiring a high threshold and careful benefit-risk considerations.

Taken together, the previous lack of available DOAC antidotes should not have been a reason in the past to withhold a DOAC prescription in eligible patients, since the benefits of providing an effective and safe anticoagulant in trial programs and observations registries were overwhelming already even before DOAC antidotes became available. Having the antidotes available today further increases the safety and hopefully improves the outcomes of major complications for DOACs in patients.

\section{Conclusions}

The availability of DOACs for patients with AF has dramatically changed our approach to stroke prevention. Clinical evidence supporting DOAC use in extremely obese patients and in patients requiring nasogastric nutrition is mounting, which is reassuring that the therapeutic window of DOAC may be even greater than previously expected. However, severe renal impairment, ESRD, and rates and management of major bleeding or thromboembolic complications during DOAC therapy remain frequent concerns in daily care and much more research is needed in these common clinical situations.

\section{Conflict of Interest}

JB-W has received honoraria from Alexion, Bayer, Daiichi Sankyo, Medscape, Pfizer, and Portola, and research funding from Bayer, Boehringer Ingelheim, Daiichi Sankyo, Pfizer, and Portola.

\section{References}

1 Wolf PA, Abbott RD, Kannel WB. Atrial fibrillation as an independent risk factor for stroke: the Framingham Study. Stroke 1991;22 (08):983-988

2 Kirchhof P, Benussi S, Kotecha D, et al;ESC Scientific Document Group. 2016 ESC Guidelines for the management of atrial fibrilla- tion developed in collaboration with EACTS. Eur Heart J 2016;37 (38):2893-2962

3 Kirchhof P, Ammentorp B, Darius H, et al. Management of atrial fibrillation in seven European countries after the publication of the 2010 ESC Guidelines on atrial fibrillation: primary results of the PREvention oF thromboembolic events-European Registry in Atrial Fibrillation (PREFER in AF). Europace 2014;16(01):6-14

4 Patel MR, Mahaffey KW, Garg J, et al;ROCKET AF Investigators. Rivaroxaban versus warfarin in nonvalvular atrial fibrillation. $\mathrm{N}$ Engl J Med 2011;365(10):883-891

5 Connolly SJ, Ezekowitz MD, Yusuf S, et al;RE-LY Steering Committee and Investigators. Dabigatran versus warfarin in patients with atrial fibrillation. N Engl J Med 2009;361(12):1139-1151

6 Granger CB, Alexander JH, McMurray JJ, et al;ARISTOTLE Committees and Investigators. Apixaban versus warfarin in patients with atrial fibrillation. N Engl J Med 2011;365(11):981-992

7 Giugliano RP, Ruff CT, Braunwald E, et al;ENGAGE AF-TIMI 48 Investigators. Edoxaban versus warfarin in patients with atrial fibrillation. N Engl J Med 2013;369(22):2093-2104

8 Ruff CT, Giugliano RP, Braunwald E, et al. Comparison of the efficacy and safety of new oral anticoagulants with warfarin in patients with atrial fibrillation: a meta-analysis of randomised trials. Lancet 2014;383(9921):955-962

9 Bristol-Myers Squibb-Pfizer. Eliquis 5 mg film-coated tablets Summary of product characteristics 2020 . Available from: https://www. medicines.org.uk/emc/product/2878/smpc

10 Boehringer-Ingelheim. Pradaxa $150 \mathrm{mg}$ hard capsules Summary of product characteristics 2020. Available from: http://www. medicines.org.uk/EMC/medicine/24839/SPC/Pradaxa+150

11 Daiichi Sankyo UK Limited. Lixiana 60mg Film-Coated Tablets Summary of product characteristics 2020. Available from: https://www.medicines.org.uk/emc/product/6905/smpc

12 Bayer Pharma AG. Xarelto $20 \mathrm{mg}$ film-coated tablets Summary of product characteristics 2019. Available from: https://www.medicines.org.uk/emc/product/2793/smpc

13 Gong IY, Kim RB. Importance of pharmacokinetic profile and variability as determinants of dose and response to dabigatran, rivaroxaban, and apixaban. Can J Cardiol 2013;29(7, Suppl):S24-S33

14 Reilly PA, Lehr T, Haertter S, et al;RE-LY Investigators. The effect of dabigatran plasma concentrations and patient characteristics on the frequency of ischemic stroke and major bleeding in atrial fibrillation patients: the RE-LY Trial (Randomized Evaluation of Long-Term Anticoagulation Therapy). J Am Coll Cardiol 2014;63 (04):321-328

15 Yao X, Shah ND, Sangaralingham LR, Gersh BJ, Noseworthy PA. Non-vitamin $\mathrm{K}$ antagonist oral anticoagulant dosing in patients with atrial fibrillation and renal dysfunction. J Am Coll Cardiol 2017;69(23):2779-2790

16 Steinberg BA, Shrader P, Thomas L, et al;ORBIT-AF Investigators and Patients. Off-label dosing of non-vitamin $\mathrm{K}$ antagonist oral anticoagulants and adverse outcomes: the ORBIT-AF II registry. J Am Coll Cardiol 2016;68(24):2597-2604

17 Yu HT, Yang PS, Jang E, et al. Label adherence of direct oral anticoagulants dosing and clinical outcomes in patients with atrial fibrillation. J Am Heart Assoc 2020;9(12):e014177

18 Lee KN, Choi JI, Boo KY, et al. Effectiveness and safety of off-label dosing of non-vitamin $\mathrm{K}$ antagonist anticoagulant for atrial fibrillation in Asian patients. Sci Rep 2020;10(01):1801

19 Ruff CT, Giugliano RP, Braunwald E, et al. Association between edoxaban dose, concentration, anti-Factor Xa activity, and outcomes: an analysis of data from the randomised, double-blind ENGAGE AF-TIMI 48 trial. Lancet 2015;385(9984):2288-2295

20 XARELTO ${ }^{\circ}$ (rivaroxaban). Tablets Prescribing Information: Janssen Pharmaceuticals, Inc.; 2020 [03/2020]. Accessed January 11, 2021 at: https://www.accessdata.fda.gov/drugsatfda_docs/label/ 2020/202439s031,022406s035lbl.pdf

21 Königsbrügge $\mathrm{O}, \mathrm{Ay} \mathrm{C}$. Atrial fibrillation in patients with end-stage renal disease on hemodialysis: magnitude of the problem and 
new approach to oral anticoagulation. Res Pract Thromb Haemost 2019;3(04):578-588

22 COUMADIN (warfarin sodium). Tablets Prescribing Information: Bristol-Myers Squibb Company; 2011 [10/2011]. Accessed January 11, 2021 at: https://www.accessdata.fda.gov/ drugsatfda_docs/label/2011/009218s107lbl.pdf

23 Kuno T, Takagi H, Ando T, et al. Oral anticoagulation for patients with atrial fibrillation on long-term hemodialysis. J Am Coll Cardiol 2020;75(03):273-285

24 Van Der Meersch H, De Bacquer D, De Vriese AS. Vitamin K antagonists for stroke prevention in hemodialysis patients with atrial fibrillation: a systematic review and meta-analysis. Am Heart J 2017;184:37-46

25 De Vriese AS, Caluwé R, Pyfferoen L, et al. Multicenter randomized controlled trial of vitamin $\mathrm{K}$ antagonist replacement by rivaroxaban with or without vitamin K2 in hemodialysis patients with atrial fibrillation: the Valkyrie study. J Am Soc Nephrol 2020;31 (01):186-196

26 Siontis KC, Zhang X, Eckard A, et al. Outcomes associated with apixaban use in patients with end-stage kidney disease and atrial fibrillation in the United States. Circulation 2018;138(15): 1519-1529

27 Miao B, Sood N, Bunz TJ, Coleman CI. Rivaroxaban versus apixaban in non-valvular atrial fibrillation patients with end-stage renal disease or receiving dialysis. Eur J Haematol 2020;104(04):328-335

28 Mavrakanas TA, Garlo K, Charytan DM. Apixaban versus no anticoagulation in patients undergoing long-term dialysis with incident atrial fibrillation. Clin J Am Soc Nephrol 2020;15(08):1146-1154

29 Chan KE, Edelman ER, Wenger JB, Thadhani RI, Maddux FW. Dabigatran and rivaroxaban use in atrial fibrillation patients on hemodialysis. Circulation 2015;131(11):972-979

30 Vranckx P, Valgimigli M, Heidbuchel H. The significance of drugdrug and drug-food interactions of oral anticoagulation. Arrhythm Electrophysiol Rev 2018;7(01):55-61

31 Steffel J, Verhamme P, Potpara TS, et al;ESC Scientific Document Group. The 2018 European Heart Rhythm Association Practical Guide on the use of non-vitamin K antagonist oral anticoagulants in patients with atrial fibrillation. Eur Heart J 2018;39(16): 1330-1393

32 SAVAYSA $^{\mathrm{TM}}$ (edoxaban). Tablets Prescribing Information Parsippany; New Jersey, United States: Daiichi Sankyo, Inc.; 2020 [04/2020]. Accessed January 11, 2021 at: https://www.accessdata.fda.gov/drugsatfda_docs/label/2020/206316s016lbl.pdf

33 ELIQUIS (apixaban). Tablets Prescribing Information Princeton, New Jersey, United States: Bristol-Myers Squibb Company; 2020 [11/2019]. Accessed January 11, 2021 at: https://www.accessdata.fda.gov/drugsatfda_docs/label/2019/202155s024lbl.pdf

34 PRADAXA® (dabigatran etexilate mesylate). Tablets Prescribing Information; Ridgefield, Connecticut, United States: Boehringer Ingelheim Pharmaceuticals, Inc.; 2020 [07/2020]. Accessed January 11, 2021 at: https://www.accessdata.fda.gov/drugsatfda_docs/label/2020/022512s039lbl.pdf

35 Lucijanic M, Jurin I, Jurin $\mathrm{H}$, et al. Patients with higher body mass index treated with direct / novel oral anticoagulants (DOAC/NOAC) for atrial fibrillation experience worse clinical outcomes. Int J Cardiol 2020;301:90-95

36 Güler E, Babur Güler G, Demir GG, Hatipoğlu S. A review of the fixed dose use of new oral anticoagulants in obese patients: Is it really enough? Anatol J Cardiol 2015;15(12):1020-1029

37 De Caterina R, Lip GYH. The non-vitamin K antagonist oral anticoagulants (NOACs) and extremes of body weight-a systematic literature review. Clin Res Cardiol 2017;106(08):565-572

38 Martin K, Beyer-Westendorf J, Davidson BL, Huisman MV, Sandset PM, Moll S. Use of the direct oral anticoagulants in obese patients: guidance from the SSC of the ISTH. J Thromb Haemost 2016;14 (06):1308-1313

39 Proietti M, Guiducci E, Cheli P, Lip GY. Is there an obesity paradox for outcomes in atrial fibrillation? A systematic review and meta- analysis of non-vitamin $\mathrm{k}$ antagonist oral anticoagulant trials. Stroke 2017;48(04):857-866

40 Sandhu RK, Ezekowitz J, Andersson U, et al. The 'obesity paradox' in atrial fibrillation: observations from the ARISTOTLE (Apixaban for Reduction in Stroke and Other Thromboembolic Events in Atrial Fibrillation) trial. Eur Heart J 2016;37(38):2869-2878

41 Balla SR, Cyr DD, Lokhnygina Y, et al. Relation of risk of stroke in patients with atrial fibrillation to body mass index (from patients treated with rivaroxaban and warfarin in the rivaroxaban once daily oral direct factor Xa inhibition compared with vitamin $\mathrm{K}$ antagonism for prevention of stroke and embolism trial in atrial fibrillation trial). Am J Cardiol 2017;119(12): 1989-1996

42 Boriani G, Ruff CT, Kuder JF, et al. Relationship between body mass index and outcomes in patients with atrial fibrillation treated with edoxaban or warfarin in the ENGAGE AF-TIMI 48 trial. Eur Heart J 2019;40(19):1541-1550

43 Costa OS, Beyer-Westendorf J, Ashton V, et al. Effectiveness and safety of rivaroxaban versus warfarin in obese patients with acute venous thromboembolism: analysis of electronic health record data. J Thromb Thrombolysis 2020

44 Perales IJ, San Agustin K, DeAngelo J, Campbell AM. Rivaroxaban versus warfarin for stroke prevention and venous thromboembolism treatment in extreme obesity and high body weight. Ann Pharmacother 2020;54(04):344-350

45 Kushnir M, Choi Y, Eisenberg R, et al. Efficacy and safety of direct oral factor Xa inhibitors compared with warfarin in patients with morbid obesity: a single-centre, retrospective analysis of chart data. Lancet Haematol 2019;6(07):e359-e365

46 Spyropoulos AC, Ashton V, Chen YW, Wu B, Peterson ED. Rivaroxaban versus warfarin treatment among morbidly obese patients with venous thromboembolism: comparative effectiveness, safety, and costs. Thromb Res 2019;182:159-166

47 Martin AC, Thomas W, Mahir Z, et al. Direct oral anticoagulant concentrations in obese and high body weight patients: a cohort study. Thromb Haemost 2020 (e-pub ahead of print). Doi: 10.1055/s-0040-1715834

48 Piran S, Traquair H, Chan N, Bhagirath V, Schulman S. Peak plasma concentration of direct oral anticoagulants in obese patients weighing over 120 kilograms: a retrospective study. Res Pract Thromb Haemost 2018;2(04):684-688

49 Netley J, Howard K, Wilson W. Effects of body mass index on the safety and effectiveness of direct oral anticoagulants: a retrospective review. J Thromb Thrombolysis 2019;48(03):359-365

50 Tittl L, Endig S, Marten S, Reitter A, Beyer-Westendorf I, BeyerWestendorf J. Impact of BMI on clinical outcomes of NOAC therapy in daily care - results of the prospective Dresden NOAC Registry (NCT01588119). Int J Cardiol 2018;262:85-91

51 Mahlmann A, Gehrisch S, Beyer-Westendorf J. Pharmacokinetics of rivaroxaban after bariatric surgery: a case report. J Thromb Thrombolysis 2013;36(04):533-535

52 Kuramatsu JB, Sembill JA, Huttner HB. Reversal of oral anticoagulation in patients with acute intracerebral hemorrhage. Crit Care 2019;23(01):206

53 Milling TJ Jr, Frontera J. Exploring indications for the use of direct oral anticoagulants and the associated risks of major bleeding. Am J Manag Care 2017;23(4, Suppl):S67-S80

54 Piccini JP, Garg J, Patel MR, et al;ROCKET AF Investigators. Management of major bleeding events in patients treated with rivaroxaban vs. warfarin: results from the ROCKET AF trial. Eur Heart J 2014;35(28):1873-1880

55 Peck KA, Calvo RY, Schechter MS, et al. The impact of preinjury anticoagulants and prescription antiplatelet agents on outcomes in older patients with traumatic brain injury. J Trauma Acute Care Surg 2014;76(02):431-436

56 Prexl O, Bruckbauer M, Voelckel W, et al. The impact of direct oral anticoagulants in traumatic brain injury patients greater than 60 years-old. Scand J Trauma Resusc Emerg Med 2018;26(01):20 
57 Bruckbauer M, Prexl O, Voelckel W, et al. Impact of direct oral anticoagulants in patients with hip fractures. J Orthop Trauma 2019;33(01):e8-e13

58 Pollack CV Jr, Reilly PA, van Ryn J, et al. Idarucizumab for dabigatran reversal - full cohort analysis. N Engl J Med 2017; 377(05):431-441

59 Connolly SJ, Milling TJ Jr, Eikelboom JW, et al;ANNEXA-4 Investigators. Andexanet alfa for acute major bleeding associated with factor Xa inhibitors. N Engl J Med 2016;375(12):1131-1141

60 January CT, Wann LS, Calkins H, et al. 2019 AHA/ACC/HRS focused update of the $2014 \mathrm{AHA} / \mathrm{ACC} / \mathrm{HRS}$ Guideline for the management of patients with atrial fibrillation: a report of the American College of Cardiology/American Heart Association Task Force on Clinical Practice Guidelines and the Heart Rhythm Society in Collaboration With the Society of Thoracic Surgeons. Circulation 2019;140(02):e125-e151

61 Cuker A, Burnett A, Triller D, et al. Reversal of direct oral anticoagulants: guidance from the anticoagulation forum. Am J Hematol 2019;94(06):697-709

62 Christensen H, Cordonnier C, Kõrv J, et al. European stroke organisation guideline on reversal of oral anticoagulants in acute intracerebral haemorrhage. Eur Stroke J 2019;4(04):294-306 